\title{
Splenic lymphoma with villous lymphocytes in two sisters
}

\author{
I Ribeiro, M M Costa, B A Fernandes, I Sousa, A Melo, A Parreira, L Sousa Uva
}

\begin{abstract}
Splenic lymphoma with villous lymphocytes is a new entity characterised by the presence of atypical lymphocytes in the peripheral blood and bone marrow, and splenic infiltration in the white and red pulp. Cell membrane markers are those of a B mature cell, and no particular chromosomal abnormalities have been associated with this disease. A case of this rare lymphoma occurred in two sisters. Histological examination of splenic tissue was identical in both cases, with the same immunological surface markers, although the clinical and laboratory features were different. Karyotype analysis showed an abnormal pattern in one case; no environmental causative factor could be detected.
\end{abstract}

Familial cases of other lymphoproliferative disorders have been reported, but no consistent common link has been found. It is suggested that further reports of this lymphoma, including cytogenetic and molecular studies, may provide a better understanding of the aetiology.

$(\Im$ Clin Pathol 1992;45:1111-1113)

Splenic lymphoma with villous lymphocytes (SLVL) is a recently described entity, with well defined clinical, morphological, and immunological characteristics. ${ }^{15}$ We report the cases of two sisters with this particular type of lymphoma. The occurrence of other lymphoproliferative disorders, such as chronic lymphocytic leukaemia (CLL) and hairy cell leukaemia (HCL) in the same family, has already been reported ${ }^{6}$; we believe this is the first report of SLVL in siblings.

\section{Lisbon \\ I Ribeiro \\ B A Fernandes \\ L Sousa Uva}

Hospital St" Marta,

Lisbon

M M Costa

Hospital Universitário dé Coimbra, Lisbon

I Sousa

Faculdade dé Medicina dé Lisbon

A Melo

Instituto Português de Oncologia, Lisbon A Parreira

Correspondence to:

Dr Isabel Ribeiro,

Servico de Medicina A,

Hospital Egas Moniz, Rua

Hospital Egas Moniz, Rua

Lisbon, Jortugal

Accepted for publication

8 June 1992

\section{Case report}

CASE 1

In June 1989 a 66 year old woman was referred for investigation of splenomegaly and lymphocytosis. She had a four year history of weight loss, night sweats, and abdominal pain. The patient had a sister who had had her spleen removed in 1983 for "lymphoma".

On examination she was physically well and afebrile; there were no palpable lymph nodes, the liver was palpable $5 \mathrm{~cm}$ and the spleen $16 \mathrm{~cm}$ below the costal margin. The peripheral blood count comprised: haemoglobin concentration $13.3 \mathrm{~g} / 1$; white cell count $19.7 \times 10^{9} / 1$ with $50 \%$ atypical lymphocytes (notched and villous). The platelet count was $130 \times 10^{9} / 1$; erythrocyte sedimentation rate was $5 \mathrm{~mm}$ in the first hour. A bone marrow aspirate was easy to obtain and showed normal erythropoiesis and granulopoiesis, occasional megakaryocytes and $63 \%$ atypical lymphocytes. A bone marrow biopsy specimen, previously fixed in Bouin's fluid, showed a non-paratrabecular interstitial infiltrate of small B lymphocytes with coarse chromatin, positive with the monoclonal antibodies LCA and CD20, which caused topographic distortion of residual haemopoietic tissue. There was only a slight increase in stromal reticulin content.

Markers on peripheral blood lymphocytes showed: HLA-DR 63\%; CD19 66\%; CD22 $67 \%$; CD5 12\%; HC2 2\%; FMC7 33\%; CD10 negative; CD25 negative; IgM 59\%; IgG negative; IgA negative; $\kappa$ light chain $25 \%$; $\lambda$ light chain negative; CD2 18\%; CD4 12\%; and CD8 $6 \%$.

Liver and renal function tests yielded normal results and no $M$ band was found. Direct antiglobulin test was negative and the indirect antiglobulin test was positive at $37^{\circ}$.

Chromosome studies with phytohaemagglutinin in peripheral blood and bone marrow showed a missing $X$ chromosome $(46 \mathrm{X} 0)$ in $8 \%$ and $20 \%$ of metaphases, respectively.

HLA typing was A 2,9; B21,27; DR 2,3. An abdominal computed tomography scan disclosed noticeable splenomegaly, slight liver enlargement, and no abnormal lymph nodes. A splenectomy was performed in November 1989; the spleen weighed $1500 \mathrm{~g}$. The cut sections showed white nodules with diameters varying from 2 to $5 \mathrm{~mm}$. Sections of the spleen specimen taken from several areas were fixed in $10 \%$ saline formalin, embedded in paraffin wax and stained with Giemsa for cytological detail. Immunohistochemical staining was performed with LCA, L26(CD20), UCHL1 (CD45RO), $\kappa$ and $\lambda$ light chains, IgM, IgG and IgA. Histological examination showed white pulp enlargement, with coalescence of occasional follicles due to infiltration by small lymphocytes, and some evidence of plasmocytic differentiation with visible excentric cytoplasm. There was also speckled red pulp infiltration; the spatial arrangement of the lymphocytes characteristic of HCL was not seen (fig 1).

The lymphocytes in both the white and red pulp were CD20 positive and CD45RO negative; the lymphoplasmacytic cells expressed IgM and $\kappa$ light chain. $\lambda$ light chain and the other immunoglobulins were not expressed.

After splenectomy the numbers of peripheral 

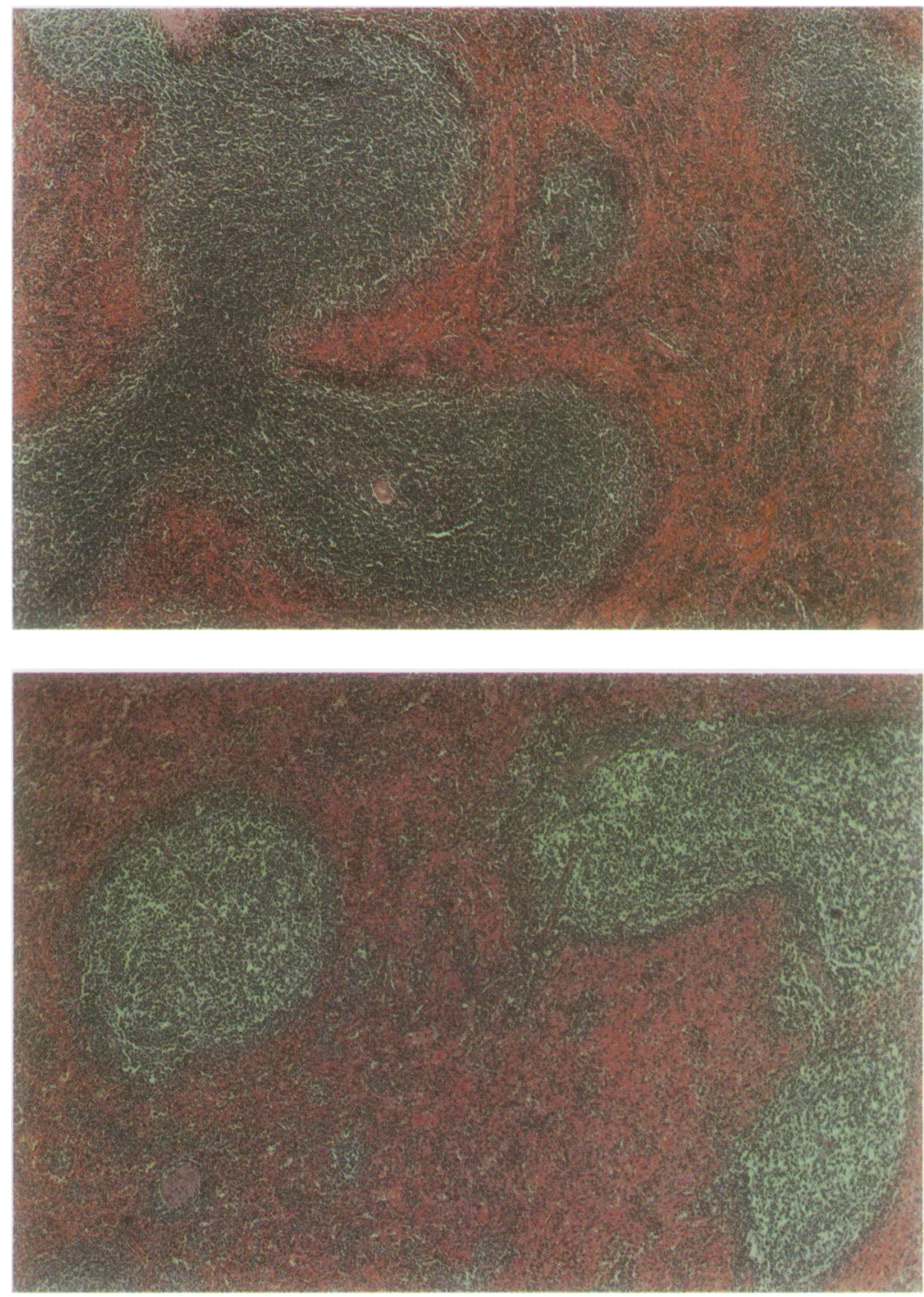

Figure 1 Case 1: Predominant white pulp enlargement due to infiltration by small lymphocytes. Scattered red pulp infiltration (haematoxylin and eosin).

Figure 2 Case 2: White pulp infiltration by small lymphocytes. White coalescence of follicles; scattered red pulp infiltration (haematoxylin and eosin).

blood villous lymphocytes rose temporarily with a gradual decrease over subsequent months. At the time of writing there were still villous lymphocytes in the peripheral blood, expressing the same markers. Repeat chromosome studies showed persistence of XO mosaicism in blood and bone marrow samples, but the karyotype of skin fibroblasts was normal. The patient remains well with no symptoms related to the lymphoma.

Current blood counts were as follows: haemoglobin concentration $15 \cdot 1 \mathrm{~g} / \mathrm{l}$; white cell count $9.6 \times 10^{9} / 1$ (neutrophils $50 \%$, lymphocytes $42 \%$; platelet count $367 \times 10^{9} / 1$.

CASE 2

A 68 year old woman presented at the Hospital Universitário de Coimbra in May 1983 complaining of left abdominal pain. There were no other symptoms and on examination she was found to have spleen palpable $8 \mathrm{~cm}$ below the costal margin but no other abnormal physical findings.

A peripheral blood count showed: haemoglobin concentration of $13.2 \mathrm{~g} / \mathrm{l}$; white cell count $6.4 \times 10^{9} /$; (neutrophils $62 \%$, eosinophils $6 \%$, lymphocytes $32 \%$ ) ; a platelet count $300 \times 10^{9} / 1$. A bone marrow aspirate was normal and no lymph nodes were disclosed by abdominal ultrasound examination.

A splenectomy was performed for diagnostic purposes. The spleen weighed $900 \mathrm{~g}$; the histological report was of a centrocytic nodular lymphoma with white and red pulp infiltration.

At the time of writing the patient remains well, with no further symptoms. Blood counts were as follows: haemoglobin $12.9 \mathrm{~g} / \mathrm{l}$; white cell count $7.5 \times 10^{9} / 1$; (neutrophils $55 \%$, eosinophils $1 \%$, lymphocytes $39 \%$ monocytes $5 \%$ ); platelet count $377 \times 10^{9} / 1$.

At the time we studied the sister (case 1) a review of spleen histology was performed. An identical pattern of white pulp infiltration with only focal red pulp infiltration by small lymphocytes and occasional lymphoplasmacytic differentiation was found, with positive immunohistochemical staining for CD20, IgM and $\kappa$ markers (fig 2). The bone marrow aspirate was not available for review. Peripheral blood karyotype was normal and HLA typing showed: A 2,3; B 27,35; DR 1,2.

There were no known malignancies in the family and no consanguinity between our patients' parents. Both sisters had healthy daughters and had lived in different regions of Portugal for the past 20 years. There was no history of occupational or other exposure to carcinogens.

\section{Discussion}

We believe this to be the first report of this unusual lymphoma in siblings. The clinical presentation in the two cases was somewhat different, with the occurrence of symptoms, lymphocytosis, and marrow disease in case 1 , and only splenomegaly in case 2 ; we think this could represent different stages in the evolution of this disorder which probably has its origin in the spleen.

It is of particular interest that the spleen histology was quite similar and that the same immunoglobulin $(\operatorname{IgM}, \kappa)$ was found on the cells in both cases.

We examined the possibility of a genetic factor for the development of this lymphoma. Chromosome analysis showed $\mathrm{XX} / \mathrm{XO}$ mosaicism in case 1 , but a normal pattern in case 2 ; the true relevance of the persistent anomaly remains to be established as it could probably be attributed to random loss.

HLA typing showed partial identity (A2; B27; DR2) as would be expected in siblings; unfortunately no other family studies were possible, and therefore no conclusions can be drawn. Some cases of lymphoproliferative disorders with HLA identity have been described, ${ }^{1011}$ but their relevance is still controversial.

A common environmental factor is very unlikely here, as both sisters lived in different places for a long time and had distinct social and occupational backgrounds. Nevertheless, the occurrence of this unusual lymphoma in 
two sisters seems unlikely to be attributable to chance. We hope that further reports of SLVL, in particular with cytogenetic and molecular studies, will clarify the pathogenesis of this condition.

We are indebted to Professor R Trincào for providing the spleen tissue of case 2 and to Dr K MacLennan for critical comments on spleen histology. We also thank Dr I Reis for performing the chromosomal studies.

1 Melo JV, Hedge V, Parreira A, Thompson I, Lampert IA, Catovsky D. Splenic B cell lymphoma with circulating villous lymphocytes: differential diagnosis of $B$ cell leukaemias with large spleens. F Clin Pathol 1987;40 642-51.

2 Bennet JM, Catovsky D, Daniel MT, et al. The FrenchAmerican-British (FAB) cooperative group proposals for the classification of chronic (mature) $B$ and $T$ lymphoid leukaemias. $\mathcal{f}$ Clin Pathol 1989;42:567-84.

3 Spriano P, Barose G, Invernezzi R, et al. Splenomegalic immunocytoma with circulating hairy cells. Report of immunocytoma with circulating hairy cells. Report of
1986;71:25-33

4 Neiman RS, Sullivan AL, Jaffe R. Malignant lymphoma simulating leukaemic reticulothendotheliosis. A clinicosimulating leukaemic reticulothendotheliosis. A clinico-

5 Melo JV, Robinson DS, Gregory C, Catovsky D. Splenic lymphoma with "villous" lymphocytes in the peripheral blood: a disorder distinct from hairy cell leukaemia. Leukaemia 1987;1:244-98.

6 Fraumeni JF jr, Vogel CL, DeVita VT. Familial chronic lymphocytic leukaemia. Ann Intern Med 1969;71: 279-84.

7 Fraumeni JF ir, Wertelecki W, Blattner W, et al. Varied manifestations of a familial lymphoproliferative disorder. Am $\mathcal{J}$ Med 1975;59:145-51.

8 Blattner WA, Strober W, Muchmore AV, Blaese RM, Broder $\mathrm{S}$, Fraumeni JF jr. Familial chronic lymphocytic leukaemia Immunologic and cellular characterization. Ann Intern Med 1976;84:554-7.

9 Blattner WA,Neiman JL, Mann DL, Wimer RS, Dean JH, Fraumeni JF. Immunogenetic determinants of familial acute leukaemia. Ann Intern Med 1978;89:173-6.

10 Ramseur WL, Golomb HM, Vardiman JW, Oleske D, Collins JL. Hairy cell leukaemia in father and son. Cancer 1981;48:1825-9.

11 Wylin RF, Greene MH, Palutke M, Khilanani P, Tabaczka $P$, Swiderski G. Hairy cell leukaemia in three siblings: an P, Swiderski G. Hairy cell leukaemia in three siblings: an
apparent HLA linked disease. Cancer 1982;49:538-42. 